\title{
Tunable multiferroic properties of cerium doped bismuth ferrite
}

\author{
Rozina Patel ${ }^{1 *}$, Pratibha Sawadh ${ }^{2}$ \\ ${ }^{1}$ Department of Physics, New Arts, Commerce and Science college, Wardha, India \\ ${ }^{2}$ Department of Physics, Bapurao Deshmukh College of Engineering, Wardha, India \\ *patel.rozina84@gmail.com
}

DOI 10.17586/2220-8054-2019-10-3-255-265

\begin{abstract}
Multiferroic $\mathrm{Bi}_{1-x} \mathrm{Ce}_{2} \mathrm{FeO}_{3}(x=0.05,0.1,0.15,0.2)$ nanoparticles were prepared using an auto-combustion method. The effect of cerium substitution on the crystal structure, electrical and magnetic properties of $\mathrm{BiFeO}_{3}$ (Bismuth Ferrite) was studied. X-raydiffraction spectra revealed that Ce substitution increases the lattice parameters. The average particle size estimated from TEM images is less than 50 nanometers. According to the magnetic hysteresis loops, it was found that the enhanced magnetization which results from increasing Ce concentration is attributed to the nanoparticle size and enhanced ferroelectric polarization. The magnetization and ferroelectric polarization were found to exhibit an exotic mutual relationship. The samples were found to exhibit relaxation of dielectric polarization. This rare combination of $\mathrm{Ce}^{\mathrm{doped}} \mathrm{BiFeO} \mathrm{O}_{3}$ by auto-combustion method has not been reported before.
\end{abstract}

Keywords: Multiferroic, nano particles, X-ray diffraction, ferroelectric, ferromagnetic

Received: 9 March 2019

Revised: 24 May 2019

\section{Introduction}

One of the reasons for fabricating novel materials for attaining rich functionality is to unite different physical properties in single material. Magnetic and Ferroelectric materials are enduring subject of study and have led to notable progress in the development of technology to date. These apparently distinct phenomena can coexist in certain unusual substances, termedas multiferroics which are of key importance, both from research as well as technological perspective.

Multiferroic materials exhibit the phenomena of ferroelectricity (FE), ferromagnetism (FM) and ferroelasticity simultaneously in their singlephase [1-3]. Although the possibility of coupling orinteraction between ferromagnetic and ferroelectric order parameters is known for quite long time, its existence and practical applications were realized only after the discovery of multiferroicity in $\mathrm{BiFeO}_{3}$.

Bismuth ferrite is found to be one such material which demonstrate a coupling between magnetic and ferroelectric order, having Curie temperature $T_{C} \approx 1100{ }^{\circ} \mathrm{K}$ and antiferromagnetic temperature $T_{N} \approx 640{ }^{\circ} \mathrm{K}$ [4, 5]. Bismuth ferrite possesses G-type antiferromagnetic ordering because of its complex cycloidal spin structure with a wavelength of $62 \mathrm{~nm}$ with [110] spiral direction and (110) spin rotation plane [6]. However $\mathrm{BiFeO}_{3}$ suffers from several major issues like phase defects such as oxygen vacancies and impurity, high leakage current, spiral spin structure, large difference in transition temperature $\left(T_{C} \& T_{N}\right)$. The leakage current a rises in $\mathrm{BiFeO}_{3}$ due to its nonstoichiometry. This is particular lybecause of the difficulty in obtaining stoichiometric singlephase $\mathrm{BiFeO}_{3}$ materials. In order to reduce leakage current density efforts have been made by using different fabrication methods. Several techniques have also been recently adopted to eliminate secondary phases and oxygen vacancies [7-11]. Particle size also plays a vital role in controlling the structural and magnetic properties of $\mathrm{BiFeO}_{3}$ [12]. The authors [13] described the necessity to lower the sintering time during the increasein synthesis temperature to confine the formed $\mathrm{BiFeO}_{3}$ crystals within the nanosize range. The current trend is to avoid brute force methods in order to have a better control of stoichiometry, structure, and phase purity of metal oxides. The authors [14]reported cerium-substituted $\mathrm{BiFeO}_{3}$ powders using hydrothermal method revealed the lattice contraction and decrease of grain size. Synthesis of Ce substituted $\mathrm{BiFeO}_{3}$ nanoflakes [15] using sol-gel method has resulted in enhancement of electrical properties. The combustion or fire synthesis is quite simple, fast, and economical. It is possible to control the particle size of solid combustion product to nano-range by using suitable fuels that control the nature of combustion. Urea is documented as an ideal fuel for the combustion synthesis of high temperature oxides [16]. In this work, auto combustion method was used for synthesis as it has not been reported for the synthesis of $\mathrm{Ce}$ doped $\mathrm{BiFeO}_{3}$ and urea was chosen as the fuel, which act as a self-catalyst and generates heat as its melting point is very low, which further helps in increasing the reactivity of the samples yielding a good result as compared to solid state process.

Attempts to improve the electrical properties have been made by doping it with rare earth elements such as lanthanum (La), samarium $(\mathrm{Sm})$, gadolinium $(\mathrm{Gd})$ and dysprosium (Dy) etc. $[17,18]$. Efforts have also been made to 
overcome these issues by doping transition metals [19] into $\mathrm{BiFeO}_{3}$, also modifying material by including solid solution of $\mathrm{BiFeO}_{3}$ with $\mathrm{BaTiO}_{3}$ etc. [20,21]. Difficulties also prevail in the practical realization of $\mathrm{BiFeO}_{3}$, resulting from weak ferromagnetism exhibited by $\mathrm{BiFeO}_{3}$, as the spiral spin modulation, superimposed on G-type antiferromagnetic spin ordering [22,23], cancels out any possible net magnetization. One means for suppressing spiral spin modulation in $\mathrm{BiFeO}_{3}$ is the chemical substitution in the A-sublattice [24-29]. Diamagnetic substitution at A-site in $\mathrm{BiFeO}_{3}$ has been shown to enhance the net magnetization of parent material because of the kind of diamagnetic dopant element [30,31].

In the present work, we have incorporated the compositional variations which have permitted the attainment of improved multiferroic properties. Cerium was chosen to substitute at $\mathrm{A}$-site of $\mathrm{BiFeO}_{3}$ because the ionic radius of $\mathrm{Ce}^{3+}$ is comparable with that of $\mathrm{Bi}^{3+}$. The electronic configuration of $\mathrm{Ce}^{3+}$ also causes hybridization resulting in formation of $\mathrm{Ce}-\mathrm{O}$ bond [32] leading to a noncentrosymmetrically distorted structure and a suppressed spiral spin structure, probably improving the ferroelectric and magnetic properties. The partial substitution of $\mathrm{Bi}^{3+}$ ions by rare earth ions are reported to improve multiferroic properties of $\mathrm{BiFeO}_{3}$ [33-37].

\section{Experimental}

The samples with the composition $\mathrm{Bi}_{1-x} \mathrm{Ce}_{x} \mathrm{FeO}_{3}(x=0.05,0.1,0.15,0.2)$ were prepared byan auto combustion method using urea as a fuel. The prime basis of auto combustion method depends on the proficiency of high lyexothermic reactions to be self-sustaining and,therefore, energetically efficient. The exothermic reaction is initiated at the ignition temperature, and generate sheat which is displayed in a maximum or combustion temperature $\left(T_{\text {comb }}\right)$, which can volatilize low boiling point impurities, and therefore result in purer products than those produced by more conventional techniques.

The precursor materials used for the synthesis of $\mathrm{Bi}_{1-x} \mathrm{Ce}_{x} \mathrm{FeO}_{3}(x=0.05,0.1,0.15,0.2)$ bythe auto combustion route were analytical reagent grade bismuth nitrate pentahydrate $\left(\mathrm{Bi}\left(\mathrm{NO}_{3}\right)_{3} \cdot 5 \mathrm{H}_{2} \mathrm{O}\right)$, ferric nitrate nonahydrate $\left(\mathrm{Fe}\left(\mathrm{NO}_{3}\right)_{3} \cdot 9 \mathrm{H}_{2} \mathrm{O}\right)$, Cerium(III) nitratehexahydrate $\left(\mathrm{Ce}\left(\mathrm{NO}_{3}\right)_{3} \cdot 6 \mathrm{H}_{2} \mathrm{O}\right)$ with a purity of more than $99 \%$. Analytical grade urea in a powder form with purity more than $99 \%$ was used as fuel in the synthesis of the $\mathrm{Bi}_{1-x} \mathrm{Ce}_{x} \mathrm{FeO}_{3}$ powder. Appropriate quantities of materials were weighed in microbalance according to the stoichiometry to obtain $(0.05,0.1,0.15,0.2)$ trivalent $\mathrm{Ce}^{3+}$ dopant concentrations to replace trivalent $\mathrm{Bi}^{3+}$. Stoichiometry of there doxmixture for combustion is calculated based on the total oxidizing and reducing valencies of oxidizer and fuel. So that the equivalent oxidizer to fuel ratio becomes unity which results in release of maximum heat $[38,39]$ :

$$
\begin{gathered}
0.8 \mathrm{Bi}\left(\mathrm{NO}_{3}\right)_{3} \cdot 5 \mathrm{H}_{2} \mathrm{O}+\mathrm{Fe}\left(\mathrm{NO}_{3}\right)_{3} \cdot 9 \mathrm{H}_{2} \mathrm{O}+0.2 \mathrm{Ce}\left(\mathrm{NO}_{3}\right)_{3} \cdot 6 \mathrm{H}_{2} \mathrm{O}+5 \mathrm{CH}_{4} \mathrm{~N}_{2} \mathrm{O} \\
\rightarrow \mathrm{Bi}_{0.8} \mathrm{Ce}_{0.2} \mathrm{FeO}_{3}(\mathrm{~s})+8 \mathrm{~N}_{2}(\mathrm{~g})+24 \mathrm{H}_{2} \mathrm{O}(\mathrm{l})+5 \mathrm{CO}_{2}(\mathrm{~g}) .
\end{gathered}
$$

According to propellant chemistry, the valencies of the elements carbon, hydrogen, nitrogen and oxygen are +4 , $+1,0$ and -2 respectively. The valency of nitrogen is taken as zero because of its conversion to molecular nitrogen during combustion. The valencies of metal depend upon metal ions in that compound. The valencies of the metals bismuth, iron and cerium are $+3,+3$ and +3 respectively. Thus, amixture of $\left(\mathrm{Bi}\left(\mathrm{NO}_{3}\right)_{3} \cdot 5 \mathrm{H}_{2} \mathrm{O}\right),\left(\mathrm{Fe}\left(\mathrm{NO}_{3}\right)_{3} \cdot 9 \mathrm{H}_{2} \mathrm{O}\right)$, $\mathrm{Ce}\left(\mathrm{NO}_{3}\right)_{3} \cdot 6 \mathrm{H}_{2} \mathrm{O}$ and urea in an appropriate molar proportion were thorough lymixed by grinding using agate mortar and pestle to form a homogeneous mixture. This homogeneous mixture was then poured into a crucible and was introduced into a $500{ }^{\circ} \mathrm{C}$ preheated mufflefurnace, which under goes self-propagating, gas producing combustion reaction to yield voluminous metal oxide in less than 5 minutes, which is a porous and foamy product [40]. The porous powder was ground in a mortar and pestle to obtain a fine powder. The ground powder was again placed into the furnace for sintering at $400{ }^{\circ} \mathrm{C}$ for 3 hours.

The samples were then characterized by using various techniques. X-raypowder diffraction data was collected using an XPERT-PRO diffractometer with $\mathrm{CuK} \alpha$ radiation $(\lambda=0.15456 \mathrm{~nm})$ at step of 0.02 in the range $2 \theta=200$ to 800 . The magnetic properties were measured by a vibrating sample magnetometer (Lakeshore VSM 7410) at room temperature. Dielectric measurements were performed on an impedance analyzer (WeynnKerr6500B) for which the sintered samples were mechanically pressed inh ydraulic press and an Ag paste was applied to both sides of the polished pellets. Ferroelectric hysteresis loops were studied by a P-E loop tracer.

\section{Result and discussion}

Room temperature powder $\mathrm{x}$-ray diffraction was then carried out on $\mathrm{Bi}_{1-x} \mathrm{Ce}_{x} \mathrm{FeO}_{3}(x=0.05,0.1,0.15,0.2)$. Rhombohedral perovskite structure is retained even after substituting $\mathrm{Ce}^{3+}$ ions for $\mathrm{Bi}^{3+}$ in $\mathrm{BiFeO}_{3}$. The profile fit for the Rietveld refinement of $\mathrm{Bi}_{1-x} \mathrm{Ce}_{x} \mathrm{FeO}_{3}(x=0.05,0.1,0.15,0.2)$ samples are shown in Fig.1(a,b,c,d) respectively. $\mathrm{Ce}$ doping causes the peaks to shift toward lower $2 \theta$ value this indicates that $\mathrm{Ce}$ is getting substituted in the $\mathrm{BiFeO}_{3}$ lattice. 


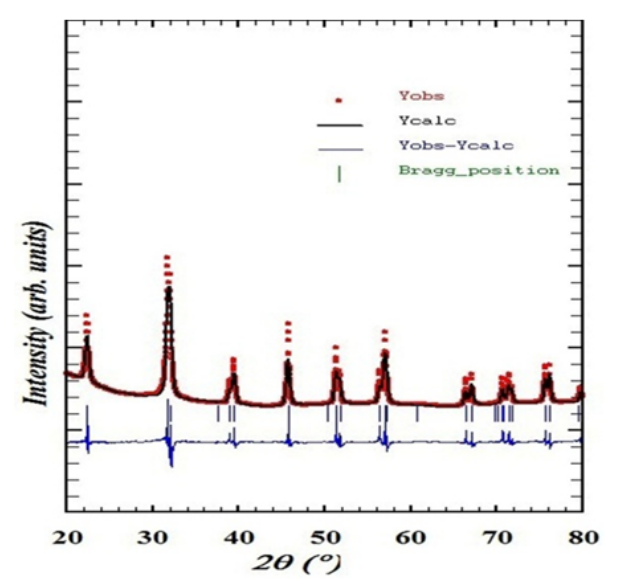

(a)

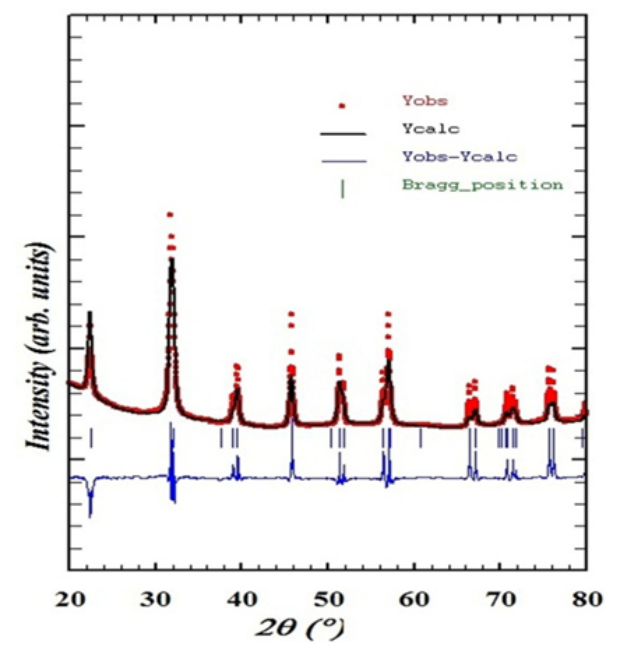

(c)

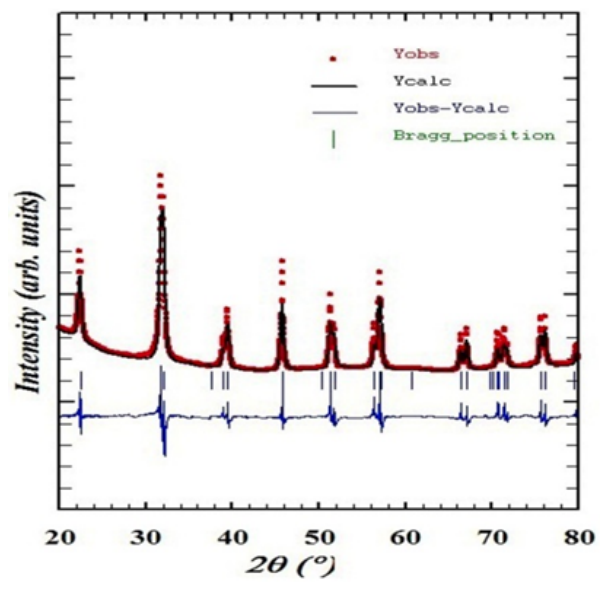

(b)

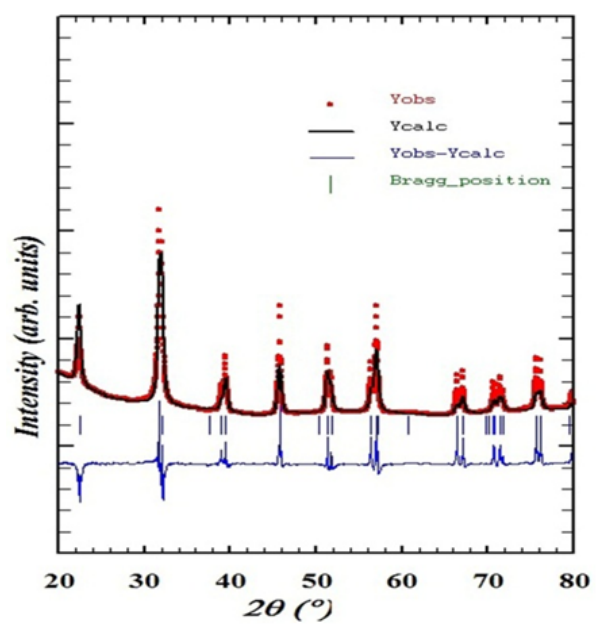

(d)

FIG. 1. The fit for the Rietveld refined profile for the $\mathrm{Bi}_{0.95} \mathrm{Ce}_{0.05} \mathrm{FeO}_{3}$ (a); $\mathrm{Bi}_{0.9} \mathrm{Ce}_{0.1} \mathrm{FeO}_{3}$ (b); $\mathrm{Bi}_{0.85} \mathrm{Ce}_{0.15} \mathrm{FeO}_{3}$ (c) and $\mathrm{Bi}_{0.8} \mathrm{Ce}_{0.2} \mathrm{FeO}_{3}(\mathrm{~d})$ samples

The lattice parameters are found to increase with Ce doping because ionic radii of $\mathrm{Ce}^{3+}$ (radius $=1.01 \AA$ ) is more than that of $\mathrm{Bi}^{3+}$ (radius = $1.03 \AA$ ) ion [41]. The crystallite sizes of all the samples $\mathrm{Bi}_{1-x} \mathrm{Ce}_{x} \mathrm{FeO}_{3}(x=0.05,0.1$, $0.15,0.2$ ) were found to be $16 \mathrm{~nm}, 19 \mathrm{~nm}, 22 \mathrm{~nm}$ and $27 \mathrm{~nm}$ respectively obtained by considering the most intense diffraction peak in the pattern using Scherer's formula.

The stimulated XRD patterns of sample coincide well with the measured XRD pattern with generally small $R$ values as illustrated in Table 1. The lattice parameters and other refined parameter are also tabulated in Table 1.

SEM micrograph of Ce doped samples exhibits finegrained structure with sharp grain boundaries with almost uniform diameter as shown in Fig. 2. The micrographs of the samples showed relatively greater homogeneity in the microstructure. Also the grain size of the samples decreases with increasing cerium in $\mathrm{BiFeO}_{3}$ which is a clear indication of incorporation of cerium into $\mathrm{BiFeO}_{3}$.

Typical TEM images of $\mathrm{Bi}_{1-x} \mathrm{Ce}_{x} \mathrm{FeO}_{3}(x=0.05,0.1,0.15,0.2)$ samples prepared by the auto combustion method is shown in Fig. 3 respectively.

The average particle size estimated from TEM images for $\mathrm{Bi}_{1-x} \mathrm{Ce}_{x} \mathrm{FeO}_{3}(x=0.05,0.1,0.15,0.2)$ were found to be $15 \mathrm{~nm}, 20 \mathrm{~nm}, 24 \mathrm{~nm}$ and $27 \mathrm{~nm}$ respectively, which is in accordance with XRD analysis. The particles are well connected with each other and are found to be approximate lysphericalin shape. The average particle size is found to decrease with Ce doping. Thus we can conclude that the substitution of Bismuth by rare-earth in multiferroic material $\mathrm{BiFeO}_{3}$ is accompanied by a significant decrease in particle size [42]. 
TABLE 1. Details of Rietveld refined XRD parameters for $\mathrm{Bi}_{1-x} \mathrm{Ce}_{x} \mathrm{FeO}_{3}$

\begin{tabular}{|c|c|c|c|c|}
\hline Parameters & $\mathrm{Bi}_{0.95} \mathrm{Ce}_{0.05} \mathrm{FeO}_{3}$ & $\mathrm{Bi}_{0.9} \mathrm{Ce}_{0.1} \mathrm{FeO}_{3}$ & $\mathrm{Bi}_{0.85} \mathrm{Ce}_{0.15} \mathrm{FeO}_{3}$ & $\mathrm{Bi}_{0.8} \mathrm{Ce}_{0.2} \mathrm{FeO}_{3}$ \\
\hline \hline $\begin{array}{c}2 \theta \text { range } \\
\text { (deg.) }\end{array}$ & $20^{\circ}$ to $80^{\circ}$ & $20^{\circ}$ to $80^{\circ}$ & $20^{\circ}$ to $80^{\circ}$ & $20^{\circ}$ to $80^{\circ}$ \\
\hline $\begin{array}{c}\text { Step size } \\
\text { (deg.) }\end{array}$ & 0.02 & 0.02 & 0.02 & 0.02 \\
\hline Wavelength & $1.5406 \mathrm{AA}$ & $1.5406 \AA$ & $1.5406 \AA$ & $1.5406 \AA$ \\
\hline Space group & $\mathrm{R} 3 \mathrm{c}$ & $\mathrm{R} 3 \mathrm{c}$ & $\mathrm{R} 3 \mathrm{c}$ & $\mathrm{R} 3 \mathrm{c}$ \\
\hline$a(\AA)$ & $5.587 \AA$ & $5.613 \AA$ & $5.643 \AA$ & $5.659 \AA$ \\
\hline$b(\AA)$ & $5.587 \AA$ & $5.613 \AA$ & $5.643 \AA$ & $5.659 \AA$ \\
\hline$c(\AA)$ & $13.876 \AA$ & $13.902 \AA$ & $13.932 \AA$ & $13.948 \AA$ \\
\hline Volume $\left(\AA^{3}\right)$ & $375.09 \AA^{3}$ & $379.3 \AA^{3}$ & $384.19 \AA^{3}$ & $386.82 \AA$ \\
\hline$R_{F}$ & 1.7 & 2.1 & 2.5 & 2.8 \\
\hline$R_{\text {Bragg }}$ & 2.95 & 2.8 & 2.6 & 2.35 \\
\hline$R_{w p}$ & 16 & 15.6 & 14.5 & 13.0 \\
\hline$R_{\text {exp }}$ & 13.8 & 14.0 & 15.6 & 17.6 \\
\hline$R_{p}$ & 12.4 & 13.5 & 14.4 & 15.4 \\
\hline$\chi^{2}$ & 1.924 & 1.804 & 1.423 & 1.34 \\
\hline
\end{tabular}
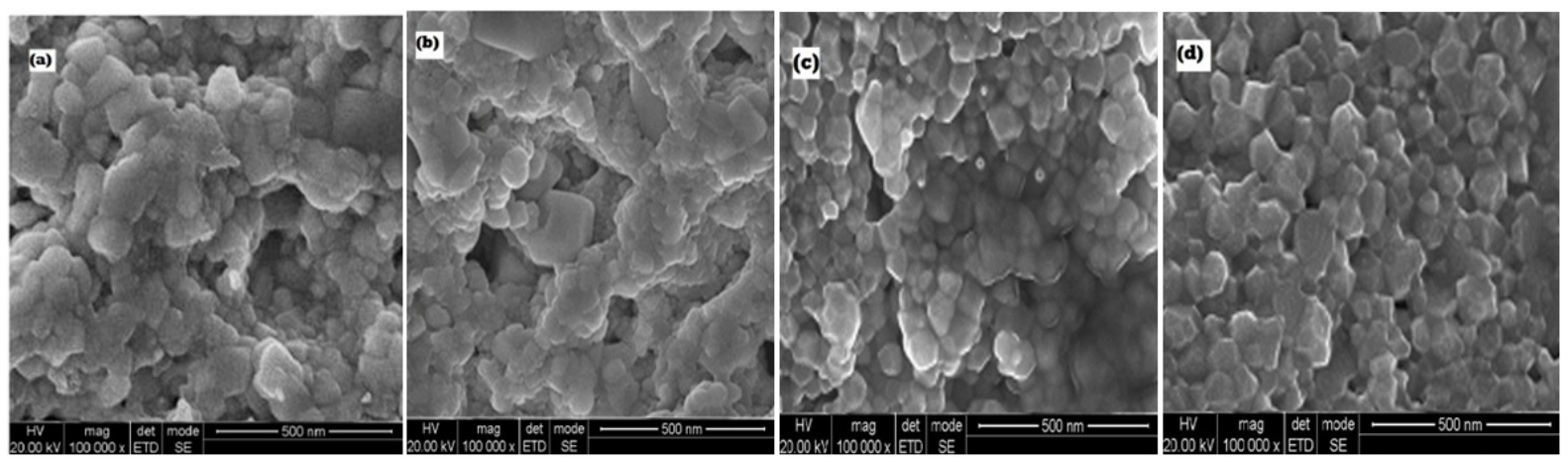

FIG. 2. SEM images of $\mathrm{Bi}_{1-x} \mathrm{Ce}_{x} \mathrm{FeO}_{3}$ nanoparticles (a) $x=0.05$; (b) $x=0.1$; (c) $x=0.15$ and (d) $x=0.2$

Thermal analysis of $\mathrm{Bi}_{1-x} \mathrm{Ce}_{x} \mathrm{FeO}_{3}(x=0.05,0.1,0.15,0.2)$ samples sintered at $400{ }^{\circ} \mathrm{C}$ has been carried out with DTA $\left(600-900{ }^{\circ} \mathrm{C}\right)$ to study the transition temperatures. DTA results for temperature range $\left(800-900{ }^{\circ} \mathrm{C}\right)$ are shown in Fig. 4. For $\mathrm{Bi}_{1-x} \mathrm{Ce}_{x} \mathrm{FeO}_{3}$ respectively. A peak is observed for all the samples. Kaczmareket al. [43] have attributed the peak observed in DTA near $830{ }^{\circ} \mathrm{C}$ to ferroelectric phase transition (Curie temperature, $T_{C}$ ) of bulk $\mathrm{BiFeO}_{3}$. This clear endothermic peak is of chief interest here.

The peak is shifted towards higher temperature with increase in Ce concentration. This increase in $T_{C}$ can be due to the decrease in pressure with increase in the cell volume. In $\mathrm{BaTiO}_{3}$, the various transition temperatures shift down on compression [44]. Similarly, lowering of ferroelectric transition temperature is observed when doped with smaller atoms [45].

The room temperature magnetic hysteresis loops for $\mathrm{Bi}_{1-x} \mathrm{Ce}_{x} \mathrm{FeO}_{3}(x=0.05,0.1,0.15,0.2)$ samples are shown in Fig. 5 recorded at $300 \mathrm{~K}$. It is noted that saturation is achieved in all the samples for an applied field of $<10 \mathrm{KOe}$. 

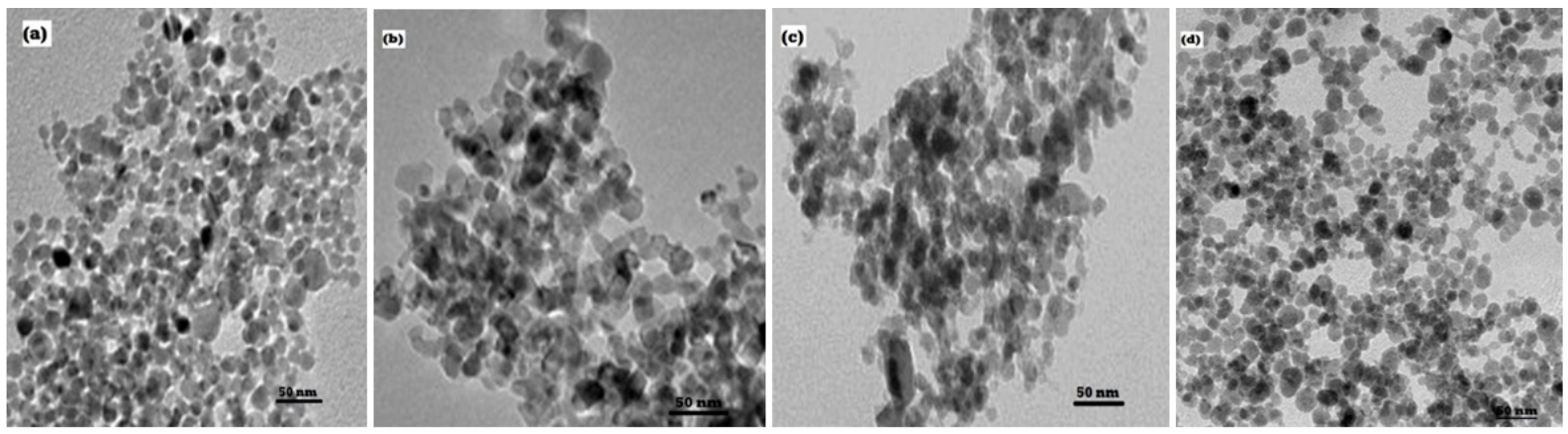

FIG. 3. TEM images of $\mathrm{Bi}_{1-x} \mathrm{Ce}_{x} \mathrm{FeO}_{3}$ nanoparticles (a) $x=0.05$; (b) $x=0.1$; (c) $x=0.15$ and (d) $x=0.2$

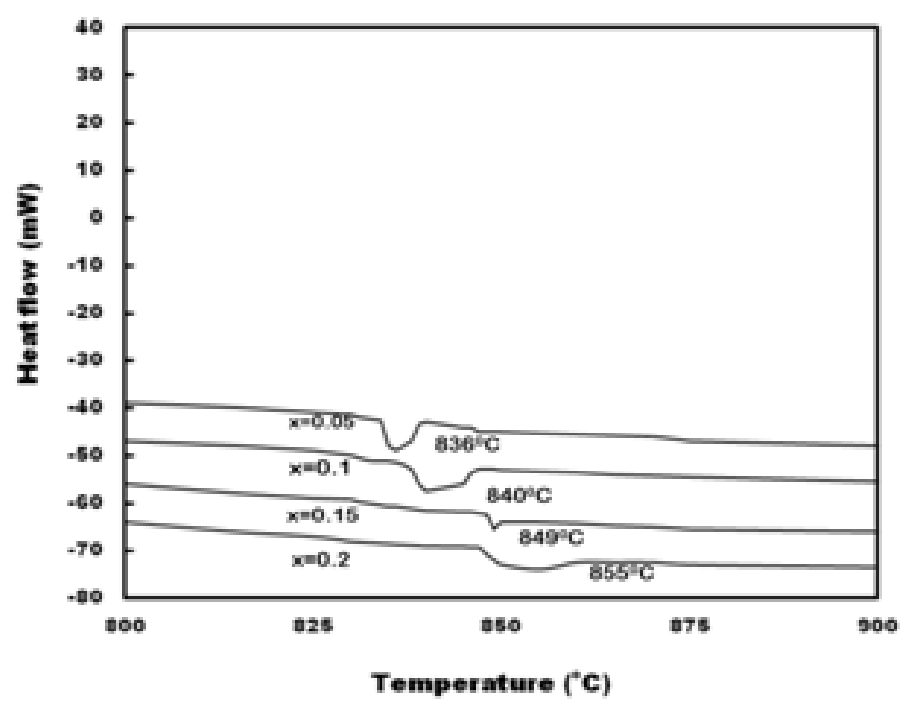

FIG. 4. DTA curve of $\mathrm{Bi}_{1-x} \mathrm{Ce}_{x} \mathrm{FeO}_{3}$ sintered at $400{ }^{\circ} \mathrm{C}$

All the samples exhibited ferromagnetic ordering at room temperature. Owing to finite size the nanoparticles usually show unusual magnetic behaviors distinct from that of their bulk counterparts. In antiferromagnetic nanoparticles, due to the large surface to volume ratio, the contribution of uncompensated spins at the surface becomes higher.

Nèel [46-48] proposed that the finite magnetic moment of nanoparticles of antiferro-magnetic materials is due to the presence of the seun compensated spin sat the surface of the particles. Apart from uncompensated spins at the surface, canting of spins in antiferromagnetic sublattices also plays an important role in the magnetic properties of the nanostructures $[49,50]$. Ce doping could have increased the canting angle, which in turn has resulted in enhanced magnetic properties. Another reason for the observed ferromagnetism is the suppression of spirals pin structure characteristic of $\mathrm{BiFeO}_{3}$. When the particle size is on the order of or $<62 \mathrm{~nm}$, this spiral spin structure changes so as to result in enhancement in magnetic properties. The variation of magnetic parameters and crystallite size is tabulated in Table 2. It is clear that $\mathrm{Ce}$ doping has strengthened the magnetic properties of $\mathrm{BiFeO}_{3}$ significantly.

Figure 6 shows $\mathrm{P}-\mathrm{E}$ hysteresis loops for the $\mathrm{Bi}_{1-x} \mathrm{Ce}_{x} \mathrm{FeO}_{3}(x=0.05,0.1,0.15,0.2)$ as a function of electric field. Ferroelectric parameters at room temperature for $\mathrm{Bi}_{1-x} \mathrm{Ce}_{x} \mathrm{FeO}_{3}(x=0.05,0.1,0.15,0.2)$ samples are given in Table 3. All samples show typical ferroelectric behavior. According to Wang et al. [51], the ferroelectricity of the $\mathrm{BiFeO}_{3}$ samples originated from the displacements of $\mathrm{Bi}$ with respect to the $\mathrm{FeO}_{6}$ cages along the (111) plane. Experimental results suggested that partial doping of $\mathrm{Ce}$ ions in $\mathrm{BiFeO}_{3}$ acts as donor in oxygen octahedron and force the reduction of oxygen vacancies by restricting the formation of $\mathrm{Fe}^{3+}$ to $\mathrm{Fe}^{2+}$ ions, resulting in a great suppression of leakage current.

It is found that remanent polarization is found to increase with an increase in crystallite size. As the grain boundary is a low permittivity region, it has weak ferroelectricity. Therefore, polarization of grain boundary may be little or 


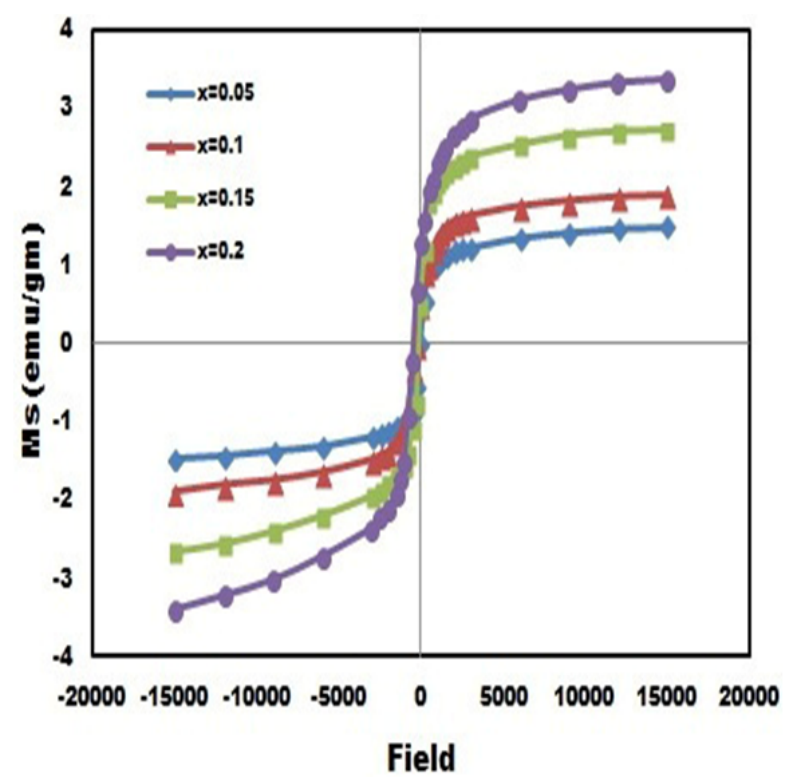

FIG. 5. The M-H plot of $\mathrm{Bi}_{1-x} \mathrm{Ce}_{x} \mathrm{FeO}_{3}(x=0.05,0.1,0.15,0.2)$ at $300 \mathrm{~K}$

TABLE 2. Details of Magnetic Parameters at Room Temperature for $\mathrm{Bi}_{1-x} \mathrm{Ce}_{x} \mathrm{FeO}_{3}$ samples

\begin{tabular}{|c|c|c|c|}
\hline Sample & $\begin{array}{c}\text { Remanent } \\
\text { Magnetization } \\
(\mathrm{emu} / \mathrm{g})\end{array}$ & $\begin{array}{c}\text { Saturation } \\
\text { Magnetization } \\
(\mathrm{emu} / \mathrm{g})\end{array}$ & $\begin{array}{c}\text { Crystallite } \\
\text { Size (nm) }\end{array}$ \\
\hline \hline $\mathrm{Bi}_{0.95} \mathrm{Ce}_{0.05} \mathrm{FeO}_{3}$ & 0.5 & 1.48 & 16 \\
\hline $\mathrm{Bi}_{0.9} \mathrm{Ce}_{0.1} \mathrm{FeO}_{3}$ & 0.7 & 1.89 & 19 \\
\hline $\mathrm{Bi}_{0.85} \mathrm{Ce}_{0.15} \mathrm{FeO}_{3}$ & 1.3 & 2.71 & 22 \\
\hline $\mathrm{Bi}_{0.8} \mathrm{Ce}_{0.2} \mathrm{FeO}_{3}$ & 1.6 & 3.38 & 27 \\
\hline
\end{tabular}

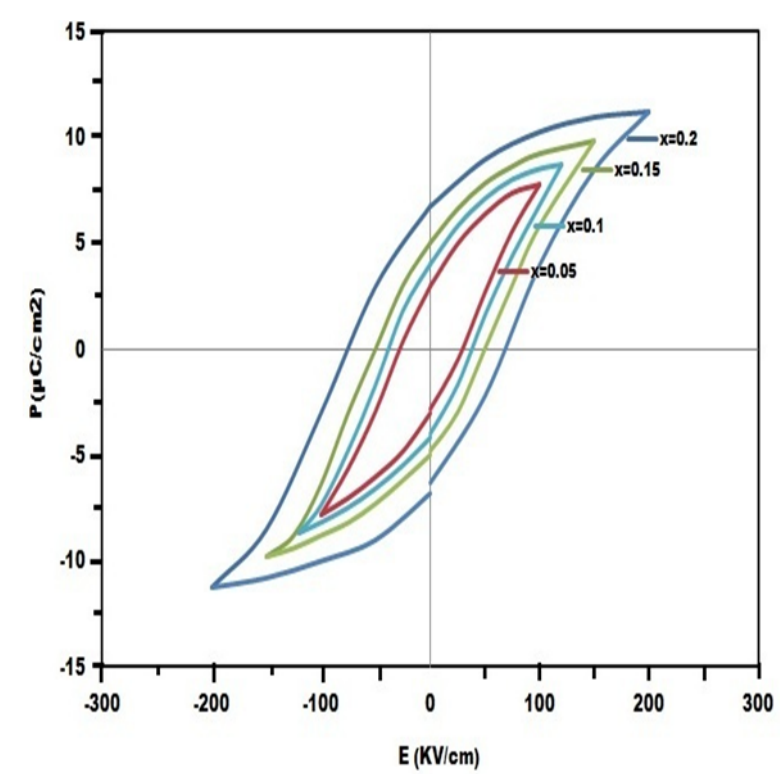

FIG. 6. Ferroelectric hysteresis loop of $\mathrm{Bi}_{1-x} \mathrm{Ce}_{x} \mathrm{FeO}_{3}(x=0.05,0.1,0.15,0.2)$ at $50 \mathrm{~Hz}$ 
TABlE 3. Details of Ferroelectric Parameters at Room Temperature for $\mathrm{Bi}_{1-x} \mathrm{Ce}_{x} \mathrm{FeO}_{3}$ samples

\begin{tabular}{|c|c|c|c|}
\hline Sample & $\begin{array}{c}\text { Electric field, } E_{c} \\
(\mathrm{KV} / \mathrm{cm})\end{array}$ & $\begin{array}{c}\text { Remnant } \\
\text { polarization } P_{r} \\
\left(\mu \mathrm{C} / \mathrm{cm}^{2}\right)\end{array}$ & $\begin{array}{c}\text { Crystallite } \\
\text { Size }(\mathrm{nm})\end{array}$ \\
\hline $\mathrm{Bi}_{0.95} \mathrm{Ce}_{0.05} \mathrm{FeO}_{3}$ & 25 & 3.08 & 16 \\
\hline $\mathrm{Bi}_{0.9} \mathrm{Ce}_{0.1} \mathrm{FeO}_{3}$ & 38 & 4.21 & 19 \\
\hline $\mathrm{Bi}_{0.85} \mathrm{Ce}_{0.15} \mathrm{FeO}_{3}$ & 46 & 5.02 & 22 \\
\hline $\mathrm{Bi}_{0.8} \mathrm{Ce}_{0.2} \mathrm{FeO}_{3}$ & 63 & 6.8 & 27 \\
\hline
\end{tabular}

even nonexistent. On the other hand, space charges in grain boundary exclude polarization charge on grain surface and depletion layer on grain surface can be formed. That results in polarization discontinuity on grain surface to form depolarization field and polarization decreases. The number of grain boundary increases as crystallite size decreases. Consequently, the remanent polarization increases as the crystallite size increases [52]. Also the remanent polarization is found to increase with Ce concentration, hence we may anticipate that replacement of highly volatile $\mathrm{Bi}^{3+}$ with $\mathrm{Ce}^{3+}$ reduces the concentration of oxygen vacancies giving reduced leakage current and thus improves ferroelectric properties.

The measured temperature dependence of dielectric constant $\varepsilon$ and loss for $\mathrm{Bi}_{1-x} \mathrm{Ce}_{x} \mathrm{FeO}_{3}(x=0.05,0.1,0.15$ and 0.2 ) samples at $100 \mathrm{~Hz}$ frequency are shown in Fig. 7(a,b), respectively. The peak in the dielectric constant is attributed to a transformation from the antiferromagnetic order to the paramagnetic order,indicating an effect of disappearing magnetic order as compared to electric order and attests to magneto-electric coupling in the samples. This type of anomaly near the Nèel temperature has also been predicted by several studies [53-58]. Here, the peaks show a diffuse nature. The substitution of cerium shifts the dielectric peak to low temperature region and a diffuse dielectric peak results. The peak shift may be attributed to the slightly larger ionic radii of $\mathrm{Ce}^{3+}$ which replaces $\mathrm{Bi}^{3+}$ due to which tolerance factor decreases which in turn reduces the Nèel temperature. Another significant result is peak broadening with increased cerium concentration.

Figure 7(b) shows the variation in dielectric loss $\tan \delta$ for $\mathrm{Bi}_{1-x} \mathrm{Ce}_{x} \mathrm{FeO}_{3}(x=0.05,0.1,0.15,0.2)$ samples. Further as noted in the dielectric constant, anomalies are observed at $390,380,374$ and $352{ }^{\circ} \mathrm{C}$ for $x=0.05,0.1$, $0.15 \& 0.2$ respectively. In addition, the peaks in dielectric constant $\varepsilon$ and dielectric loss $\tan \delta$ shifted towards a lower temperature with increased $\mathrm{Ce}^{3+}$ substitution, which indicates a decrease in the antiferromagnetic ordering temperature upon $\mathrm{Ce}^{3+}$ substitution.

Frequency $(100 \mathrm{~Hz}-1 \mathrm{MHz})$ dependence of real part of dielectric constant $\varepsilon^{\prime}$ and loss for the $\mathrm{Bi}_{1-x} \mathrm{Ce}_{x} \mathrm{FeO}_{3}$ $(x=0.05,0.1,0.15,0.2)$ samples at $300 \mathrm{~K}$ is shown in Fig. 8(a,b) respectively. For all samples, the $\varepsilon^{\prime}$ decreases with the increase in frequency and is consistent with combined response of orientational relaxation of dipoles and conduction of charge carriers. It may be attributable to the fact that the intra well hopping probability of charge carriers dominates and dipoles are unable to follow the field reversal in such a small interval of time at higher frequencies. It has been observed that $\varepsilon^{\prime}$ is increasing with substitution of Ce. Variation in $\tan \delta$ with frequency at $300 \mathrm{~K}$ for $\mathrm{Bi}_{1-x} \mathrm{Ce}_{x} \mathrm{FeO}_{3}(x=0.05,0.1,0.15,0.2)$ samples is shown in Fig. 8(a,b).

It is evident that $\tan \delta$ also decreases with an increase infrequency. The increase in the dielectric constant may be attributed to the suppression of oxygen vacancies due to the substitution of $\mathrm{Ce}^{3+}$ at $\mathrm{Bi}^{3+}$ site. Since the substitution of $\mathrm{Ce}$ at $\mathrm{Bi}$ site is ascribed to compensation of the volatile $\mathrm{Bi}$ component in $\mathrm{BiFeO}_{3}$, which causes reduction in the oxygen vacancies, which could have been generated to compensate the positive charge deficiency caused by the volatization of $\mathrm{Bi}[59,60]$. As a result, the number of oxygen vacancies decrease, therefore $\mathrm{Bi}_{0.8} \mathrm{Ce}_{0.2} \mathrm{FeO}_{3}$ has the highest $\varepsilon$ value among all the Ce doped compositions.

\section{Conclusions}

It can be concluded from the present work that auto-combustion synthesis technique can be an advantageous method to prepare single phase cerium-doped $\mathrm{BiFeO}_{3}$. The XRD pattern showed rhombohedrally distorted perovskite structure for cerium-doped $\mathrm{BiFeO}_{3}$. The crystallite size is found to increase with increasing cerium concentration. Magnetization is found to increase considerably in all doped samples due to canting of spins and particle size less than $62 \mathrm{~nm}$, which is less than the periodicity of $\mathrm{BiFeO}_{3}$. Also cerium-doped $\mathrm{BiFeO}_{3}$ sample shows fairly good ferroelectric behavior with increased remanent polarization with increasing crystallite size. Increasing the cerium concentration is found to reduce the N' eel temperature, which is observed from the temperature dependant dielectric 


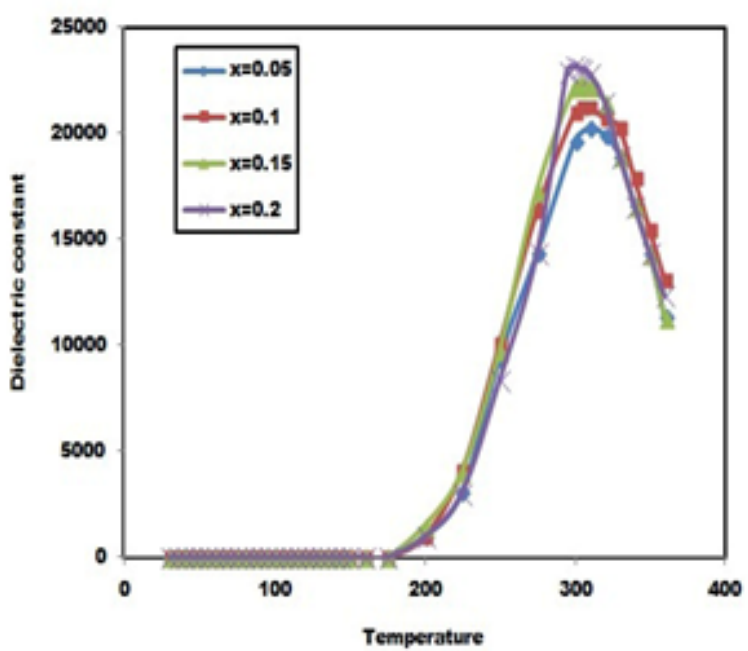

(a)

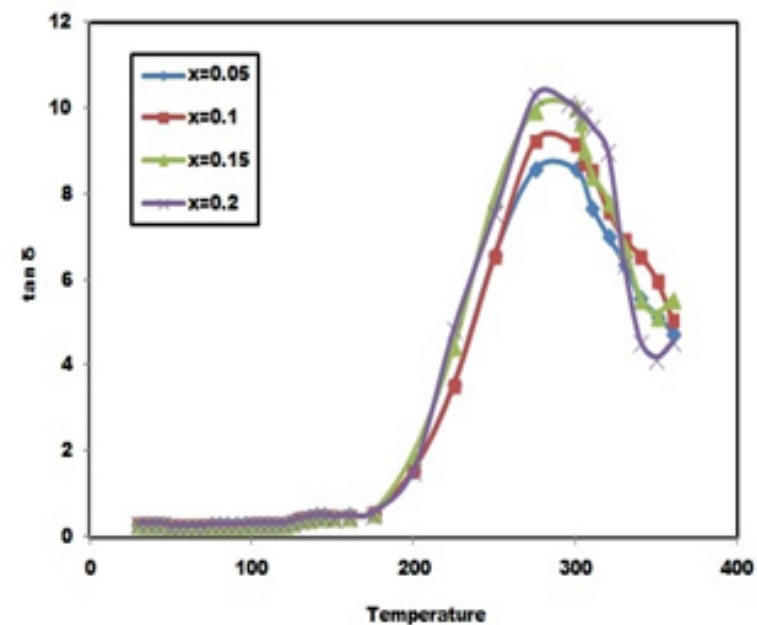

(b)

FIG. 7. (a) Temperature dependent dielectric constant at $50 \mathrm{~Hz}$; (b) Dielectric loss of $\mathrm{Bi}_{1-x} \mathrm{Ce}_{x} \mathrm{FeO}_{3}(x=0.05,0.1,0.15,0.2)$ at $50 \mathrm{~Hz}$

anomaly. This dielectric anomaly observed in all the samples is a signature of magneto-electric coupling. Dielectric constant also shows strong frequency dependence for all the samples, indicating the usual dielectric dispersion. It is anticipated that appropriate doping at $\mathrm{A}$ Site of $\mathrm{BiFeO}_{3}$ can enhance the intrinsic magnets and ferroelectric properties as well as generating novel functionalities. 


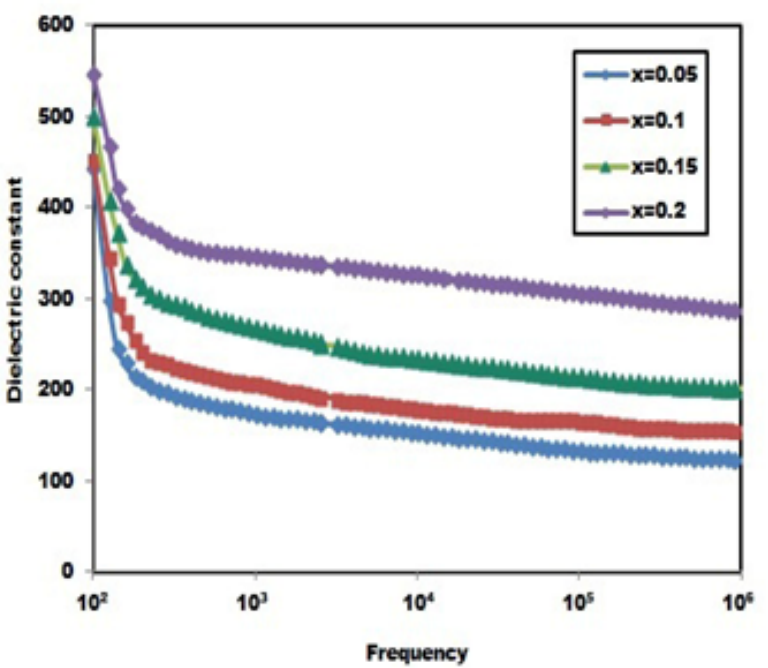

(a)

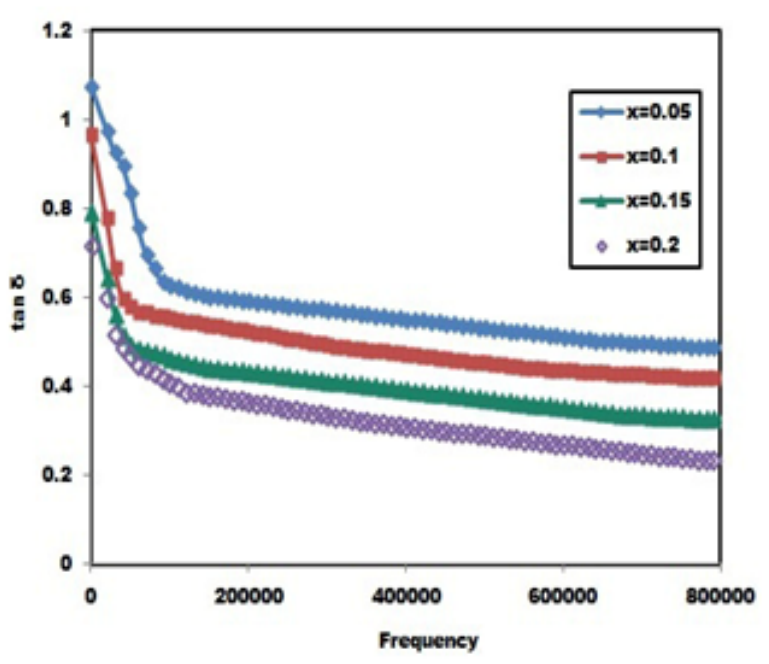

FIG. 8. (a) Real part of Frequency dependent dielectric constant; (b) Dielectric loss of $\mathrm{Bi}_{1-x} \mathrm{Ce}_{x} \mathrm{FeO}_{3}(x=0.05,0.1,0.15,0.2)$ at $300 \mathrm{~K}$

\section{References}

[1] M. Fiebig, T. Lottermoser, et al. Observation of coupled magnetic and electric domains. Nature (London), 2002, 419, P. 818-820.

[2] J. Wang, J.B. Neaton, et al. Epitaxial $\mathrm{BiFeO}_{3}$ multiferroic thin film heterostructures. Science, 2003, 299, P. 1719-1722.

[3] Rajasree Das, Gobinda Gopal Khan, Kalyan Mandal. Enhanced ferroelectric, magnetoelectric, and magnetic properties in Pr and Cr co-doped $\mathrm{BiFeO}_{3}$ nanotubes fabricated by template assisted route. J. Appl. Phys., 2012, 111, P. 104115 (1-6).

[4] Nguyen Van Minh, Nguyen Gia Quan. Structural, optical and electromagnetic properties of $\mathrm{Bi}_{1 x} \mathrm{Ho}_{x} \mathrm{FeO}_{3}$ multiferroic materials. J. Alloys Compd., 2011, 509, P. 2663-2666.

[5] Deepti Kothari, V. Raghavendra Reddy, et al. Eu doping in multiferroic $\mathrm{BiFeO}_{3}$ ceramics studied by Mossbauer and EXAFS spectroscopy. $J$. Phys.: Condens. Matter, 2010, 22, P. 356001.

[6] Sosnowska I., Loewenhaupt M., David W.I.F., Ibberson R.M. Investigation of the unusual magnetic spiral arrangement in $\mathrm{BiFeO}_{3}$. Physica B: Condensed Matter, 1992, 180-181, P. 117-118.

[7] Dho J., Qi X., et al. Large Electric Polarization and Exchange Bias in Multiferroic BiFeO 3 . ADV. Mater, 2006, 18, P.1445-1448.

[8] Xiaoding Qi, Joonghoe Dho, et al. Greatly reduced leakage current and conduction mechanism in aliovalent-ion-doped BiFeO 3 . Appl. Phys. Lett., 2005, 86, P. 062903.

[9] Can Wang, Mitsue Takahashi, et al. Leakage current of multiferroic $\left(\mathrm{Bi}_{0.6} \mathrm{~Tb}_{0.3} \mathrm{La}_{0.1}\right) \mathrm{FeO}_{3}\left(\mathrm{Bi}_{0.6} \mathrm{~Tb}_{0.3} \mathrm{La}_{0.1}\right) \mathrm{FeO}$ thin films grown at various oxygen pressures by pulsed laser deposition and annealing effect. Journal of Applied Physics, 2006, 99, P. 054104.

[10] Xiao X.H., Zhu J., et al. Greatly reduced leakage current in $\mathrm{BiFeO}_{3}$ thin film by oxygen ion implantation. Journal of Physics D: Applied Physics, 2007, 40, P. 18.

[11] Chen Y.B., Katz M.B., Pan, Ferroelectric domain structures of epitaxial (001) $\mathrm{BiFeO}_{3}$ thin films. Appl. Phys. Lett., 2007,90 , P. 072907.

[12] Samar Layek, Soumen Kumar Bag, Verma H.C. Preparation And Studies On $(1-X) \mathrm{BiFeO}_{3}-X \mathrm{Li}_{0.5} \mathrm{Fe}_{2.5} \mathrm{O}_{4}(X=0.25$ and 0.5$)$ Multiferroic Nano-Composites. 'ICNANO 2011', 2013, 4, P. 26-30. 
[13] Lomanova N.A., Gusarov V.V. Influence of synthesis temperature on $\mathrm{BiFeO}_{3}$ nanoparticles formation. Nanosystems: Physics, Chemistry, Mathematics, 2013, 4 (5), P. 696-705.

[14] Mao J., Cao L., et al. Experimental and first principles investigation of $\mathrm{Bi}_{1-x} \mathrm{Ce}_{x} \mathrm{FeO}_{3}$ : Structure, electronic and optical properties. Journal of Alloys and Compound, 2017, 721, P. 638-645.

[15] El-Lateef H., Khalaf M., Ibrahim E.M.M. Magnetic and DC electric properties of solgel synthesized Ce-doped BiFeO 3 nanoflakes. Applied Physics A, 2017, 123, P. 533.

[16] Patil K.C., Hegde M.S., Rattan T., Aruna S.T. Chemistry of nanocrystalline oxide materials - combustion synthesis: Properties and Applications, World Scientific, (2008).

[17] Gurmeet Singh Lotey, Verma N.K. Multiferroism in rare earth metals-doped $\mathrm{BiFeO}_{3}$ nanowires. Superlattices and Microstructures, 2013, 60, P. 60-66.

[18] Yao Y.B., Liuc W.C., Mak C.L. Pyroelectric properties and electrical conductivity in samarium doped BiFeO 3 ceramics. Journal of Alloys and Compounds, 2012, 527, P. 157-162.

[19] Kumar M., Yadav K.L. Rapid liquid phase sintered Mn doped $\mathrm{BiFeO}_{3}$ ceramics with enhanced polarization and weak magnetization. Appl. Phys. Lett., 2007, 91, P. 242901.

[20] Ueda K., Tabata H., Kawai T. Coexistence of ferroelectricity and ferromagnetism in $\mathrm{BiFeO}_{3}-\mathrm{BaTiO}_{3}$ thin films at room temperature. Appl. Phys. Lett., 1999, 75, P. 555.

[21] Mahesh Kumar M., Srinivas A., Suryanarayan. Structure property relations in $\mathrm{BiFeO}_{3} / \mathrm{BaTiO}_{3}$ solid solutions. Journal of Applied Physics, 2000, 87, P. 855-862.

[22] Sosnowska I., Peterlin-Neumaier T., Steichele E. Spiral magnetic ordering in bismuth ferrite. J. Phys. C: Solid State Phys., 1982, 15, P. 48354846.

[23] Przeniosto R., Palewicz A., et al. Does the modulated magnetic structure of $\mathrm{BiFeO}_{3}$ change at low temperatures? J. Phys.: Condens. Matter, 2006, 18, P. 2069-2075.

[24] Yuan G.L., Or S.W., Chan H.L.W. Structural transformation and ferroelectricparaelectric phase transition in $\mathrm{Bi}_{1 x} \mathrm{La}_{x} \mathrm{FeO}_{3}(x=0-0.25)$ multiferroic ceramics. J. Phys. D: Appl. Phys., 2007, 40, P. 1196-1200.

[25] Yuan G.L., Or S.W. Enhanced piezoelectric and pyroelectric effects in single-phase multiferroic $\mathrm{Bi}_{1 x} \mathrm{Nd}_{x} \mathrm{FeO}_{3}(x=0-0.15)$ ceramics. Appl. Phys. Lett., 2006, 88, P. 062905.

[26] Khomchenko V.A., Kiselev D.A., et al. Effect of diamagnetic $\mathrm{Ca}, \mathrm{Sr}, \mathrm{Pb}$, and Ba substitution on the crystal structure and multiferroic properties of the $\mathrm{BiFeO}_{3}$ perovskite. Journal of Applied Physics, 2008, 103, P. 024105.

[27] Fujino S., Murakami M., et al. Combinatorial discovery of a lead-free morphotropic phase boundary in a thin-film piezoelectric perovskite. Appl. Phys. Lett., 2008, 92, P. 202904.

[28] Yan Z., Wang K.F., et al. Processing and properties of Yb-doped $\mathrm{BiFeO}_{3}$ ceramics. Appl. Phys. Lett., 2007,91 , P. 082906.

[29] Mishra R.K., Pradhan D.K., Choudhary R.N.P., Baneriee A. Effect of yttrium on improvement of dielectric properties and magnetic switching behavior in $\mathrm{BiFeO}_{3}$. J. Phys.: Condens. Matter, 2008, 20, P. 045218(1-6).

[30] Khomchenko V.A., Kiselev D.A., et al. Synthesis and multiferroic properties of $\mathrm{Bi}_{0.8} \mathrm{~A}_{0.2} \mathrm{FeO} 3(\mathrm{~A}=\mathrm{Ca}, \mathrm{Sr}, \mathrm{Pb})$ ceramics. Appl. Phys. Lett., 2007, 90, P. 242901.

[31] Khomchenko V.A., Kiselev D.A., et al. Effect of diamagnetic $\mathrm{Ca}, \mathrm{Sr}, \mathrm{Pb}$, and Ba substitution on the crystal structure and multiferroic properties of the $\mathrm{BiFeO}_{3}$ perovskite. Journal of Applied Physics, 2008, 103, P. 024105.

[32] Schaffer J.P., Saxena A., et al. The Science and Design of Engineering Materials, McGrawHill, New York, 1999.

[33] Lotey G.S., Verma N.K. Structural, magnetic, and electrical properties of Gd-doped $\mathrm{BiFeO}_{3}$ nanoparticles with reduced particle size. Journal of Nanoparticle Research, 2012, 14 (3), P. 742.

[34] Lotey G.S., Verma N.K. Phase-dependent multiferroism in Dy-doped $\mathrm{BiFeO}_{3}$ nanowires. Superlattices and Microstructures, 2013, 53, P. 184194.

[35] Lotey G.S., Verma N.K. Multiferroic properties of Tb-doped $\mathrm{BiFeO}_{3}$ nanowires. Journal of nanoparticle research, 2013 , 15 (4), P. 1553.

[36] Das R., Khan G.G., Mandal K. Pr and $\mathrm{Cr}$ co-doped $\mathrm{BiFeO}_{3}$ nanotubes: an advance multiferroic oxide material. EPJ Web of Conferences, 2013, 40, P. 15015.

[37] Wang J., Li M., et al. Synthesis and ferroelectric properties of Nd doped multiferroic $\mathrm{BiFeO}_{3}$ nanotubes. Chin. Sci. Bull., 2010, 55, P. 15941597.

[38] Prakash A.S., Khadar A.M.A., Patil K.C. Hegde M.S. Hexamethylenetetramine: A New Fuel for Solution Combustion Synthesis of Complex Metal Oxides. J. Mater. Synth. Process, 2002, 10, P. 135-141.

[39] Jain S.R., Adiga K.C., Pai Verneker V.R. A new approach to thermochemical calculations of condensed fuel-oxidizer mixtures. Combust. Flame, 1981, 40, P. 71-79.

[40] Patil K.C. Advanced ceramics: Combustion synthesis and properties. Bull. Mater. Sci., 1993, 16, P. $533-541$.

[41] Shannon R.D. Revised effective ionic radii and systematic studies of interatomic distances in halides and chalcogenides. R. D. Acta Cryst. A, 1976, 32, P. 751.

[42] Zhang Xingquan, Sui Yu, et al. Influence of diamagnetic $\mathrm{Pb}$ doping on the crystal structure and multiferroic properties of the $\mathrm{BiFeO}$, perovskite. Journal of Applied Physics, 2009, 105, P. 07D918.

[43] Kaczmarek W., Pajak Z., Polomska M. Differential thermal analysis of phase transitions in $\mathrm{Bi}_{1 x} \mathrm{La}_{x} \mathrm{FeO}_{3}$ solid solution. Solid State Commun., 1975, 17, P. 807-810.

[44] Ishidate T., Abe S. Phase Diagram of $\mathrm{BaTiO}_{3}$. Physical Review Letters, 1997, 78, P. 2397-2400.

[45] Sahu J.R., Rao C.N. Beneficial modification of the properties of multiferroic $\mathrm{BiFeO}_{3}$ by cation substitution. Solid State Sciences, 2007, 9, P. 950-954.

[46] Nèel L. Superparamagnetisme des Grains Tres Fins Antiferromagnetiques. C. R. Hebd. Sean. Acad. Sci., 1961, 252, P. 4075-4080.

[47] Nèel L. Proprietes Magnetiques des Grains Fins Antiferromagnetiques: Superparamagnetisme et Superantiferromagnetisme. J. Phys. Soc. Jpn., 1962, 17, P. 676-689.

[48] Nèel L. Antiferromagnetic Hysteresis. In Selected Works of Louis Nèel. Edited by N. Kurti. Gordon and Breach, New York, 1988 , P. $467-488$.

[49] Dzyaloshinskii I.E. Thermodynamic Theory of Weak Ferromagnetism in Antiferromagnetic Substances. Sov. Phys. JETP, 1957, 5, P. 12591272. 
[50] Moriya T. Anisotropic Superexchange Interaction and Weak Ferromagnetism. Phys. Rev., 1960, 120 (1), P. $91-98$.

[51] Wang J., Neaton J.B., et al. Epitaxial $\mathrm{BiFeO}_{3}$ multiferroic thin film heterostructures. Science, 2003, 299, P. $1719-1722$.

[52] Mudinepalli V.R., Feng L., WenChin L.I.N., Murty B.S. Effect of grain size on dielectric and ferroelectric properties of nanostructured $\mathrm{Ba}_{0.8} \mathrm{Sr}_{0.2} \mathrm{TiO}_{3}$ Ceramics. Journal of Advanced Ceramics, 2015, 4 (1), P. 46-53.

[53] Chaudhari Y.A., Mahajan C.M., Jagtap P., Bendre S.T. Structural, Magnetic and Dielectric Properties of Nano-Crystalline Ni-Doped BiFeO 3 Ceramics Formulated by Self Propagating High Temperature Synthesis. Journal of Advanced Ceramics, 2013,2 , P. 135.

[54] Kumar M., Yadav K.I, Study of Dielectric, Magnetic, Ferroelectric and Magnetoelectric Properties in the $\mathrm{PbMn}_{x} \mathrm{Ti}_{1-x} \mathrm{O}_{3} \mathrm{system}_{\mathrm{at}} \mathrm{Room}$ Temperature. Journal of Physics:Condensed Matter, 2007, 19, P. 242202.

[55] Uniyal P., Yadav K.I. Room Temperature Multiferroic Properties of Eu doped BiFeO 3 . Journal of Applied Physics, 2009,105 , P. 07D914.

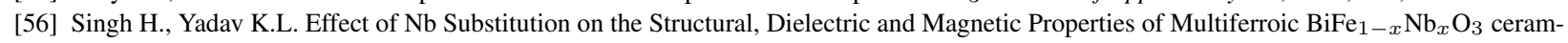
ics. Materials Chemistry and Physics, 2012, 17, P. 132.

[57] Chaudhari Y.A., Singh A., et al. Multiferroic Properties in $\mathrm{BiFe}_{1-x} \mathrm{Zn}_{x} \mathrm{O}_{3}(x=0.1-0.2)$ Ceramics by solution combustion Method (SCM). Journal of Alloys and compounds, 2008, 518, P. 51.

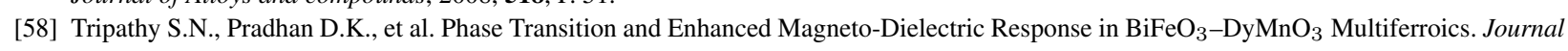
of Applied Physics, 2015, 117, Article ID: 144103.

[59] Jo S.H., Lee S.G., Lee S.H. Structural and pyroelectric properties of solgel derived multiferroic BFO thin films. Material Research Bulletin, 2012, 47 (2), P. 409-412.

[60] Makhdoom A.R., Akhtar M.J., Rafiq M.A., Hassan M.M. Investigation of transport behavior in $\mathrm{Ba}_{\text {doped }} \mathrm{BiFeO}_{3}$. Ceramics International, 2012, 38, P. 3829-3834. 